\title{
Life Satisfaction and Sense of Coherence of Breast Cancer Survivors Compared to Women with Mental Depression, Arterial Hypertension and Healthy Controls
}

\section{Salakari, Minna}

Springer-Verlag

2016

Salakari , M , Suominen , S, Nurminen, R, Sillanmaki , L, Pylkkanen , L, Rautava , P \& Koskenvuo, M 2016 , Life Satisfaction and Sense of Coherence of Breast Cancer Survivors Compared to Women with Mental Depression, Arterial Hypertension and Healthy Controls . in H Li , P Nykanen , R Suomi , N Wickramasinghe, G Widen \& M Zhan (eds), BUILDING SUSTAINABLE HEALTH ECOSYSTEMS . Communications in Computer and Information Science, vol. 636 , Springer-Verlag , Berlin , pp. 253-265, 6th International Conference on Well-Being-in-the-Information-Society (WIS) - Building Sustainable Health Ecosystems , Tampere , Finland , 16/09/2016 . https://doi.org/10.1007/978-3-319-44672-1_20

http://hdl.handle.net/10138/232554

https://doi.org/10.1007/978-3-319-44672-1_20

publishedVersion

Downloaded from Helda, University of Helsinki institutional repository.

This is an electronic reprint of the original article.

This reprint may differ from the original in pagination and typographic detail.

Please cite the original version. 


\title{
Life Satisfaction and Sense of Coherence of Breast Cancer Survivors Compared to Women with Mental Depression, Arterial Hypertension and Healthy Controls
}

\author{
Minna Salakari ${ }^{1(\bowtie)}$, Sakari Suominen ${ }^{1,2}$, Raija Nurminen ${ }^{3}$, \\ Lauri Sillanmäki ${ }^{4}$, Liisa Pylkkänen ${ }^{5}$, Päivi Rautava ${ }^{6}$, \\ and Markku Koskenvuo ${ }^{4}$ \\ ${ }^{1}$ Department of Public Health, University of Turku, Turku, Finland \\ minna.salakari@cancer.fi, sakari.suominen@utu.fi \\ ${ }^{2}$ University of Skövde, Skövde, Sweden \\ ${ }^{3}$ University of Applied Science Turku, Turku, Finland \\ raija.nurminen@turkuamk.fi \\ ${ }^{4}$ Department of Occupational Health, University of Helsinki, Helsinki, Finland \\ \{lauri.sillanmaki, markku.koskenvuo\}@helsinki.fi \\ ${ }^{5}$ Cancer Society of Finland, Helsinki, Finland \\ liisa.pylkkanen@cancer.fi \\ 6 Turku University Hospital, Turku, Finland \\ paivi.rautava@utu.fi
}

\begin{abstract}
The purpose of the study was to compare the life satisfaction (LS) and sense of coherence (SOC) of women recovering from breast cancer (BC) to LS and SOC of women with depression or hypertension and of healthy controls. Finnish Health and Social Support (HeSSup) follow-up survey data in 2003 was linked with national health registries. BC patients were followed up for mortality until the end of 2012. The statistical computations were carried out with SAS®. There were no significant differences in LS and SOC between the groups with $\mathrm{BC}$, arterial hypertension or healthy controls. Women recovering from $\mathrm{BC}$ are as satisfied with their life as healthy controls, and their perceived LS is better and SOC is stronger compared to women with depression. SOC correlated positively $\left(r^{2}=0.36, p<0.001\right)$ with LS. However, more studies on determinants of the LS are needed for designing and organizing health care services for BC survivors.
\end{abstract}

Keywords: Breast cancer $\cdot$ Breast cancer survivors $\cdot$ Comparative study $\cdot$ Life satisfaction - Sense of coherence $\cdot$ Quality of life

\section{Introduction}

Even worldwide, breast cancer (BC) is the second most common cancer and the most frequent cancer among women [1]. In Finland, in accordance with Western statistics [2], over the period 2007-2011, the annual BC incidence was more than 4,500, and the annual incidence rate was 92.6 , and the mortality rate 13.8 per 100,000 inhabitants [2]. 
Life satisfaction (LS) represents a cognitively pronounced assessment of a person's situation in life and how (s)he feels about the future. It is a measure of well-being, and the degree to which a person positively evaluates the overall quality of life (QoL). QoL is a multidimensional concept involving aspects of individuals' overall wellbeing [3], which is a state where essential needs are met and welfare increases in proportion to how far the needs are satisfied [4]. QoL may be assessed for instance in terms of mood, satisfaction with relationships, self-concepts, and self-perceived ability to cope with daily life [3-5]. It constitutes a part of the broader concepts of well-being and overall quality of life (QoL). QoL is a multidimensional concept involving aspects of individuals' overall wellbeing [3]. It may be assessed for instance in terms of mood, satisfaction with relationships, self-concepts, and self-perceived ability to cope with daily life [3-5].

For patients with cancer, LS and QoL has been determined as the patient's appraisal of satisfaction with their current level of functioning as compared with what they perceive to be possible or ideal [6]. The determinants of LS and QoL in women with $\mathrm{BC}$ include psychosocial factors, such as coping style, as well as sociodemographic and medical factors [7]. Different coping strategies have distinct effects on LS, QoL and general wellbeing in women with $\mathrm{BC}[8,9]$.

Cancer is one of the most feared diseases in modern societies and shows a strong negative impact on LS and QoL. The diagnosis of cancer evokes the feeling of stress, fear, sorrow, anger and uncertainty [10-12] and clinically significant depression is typically associated with BC $[13,14]$. Depression has also been shown to impair general QoL [15] and individuals continue to report high levels of psychological stress and depression, even once cancer treatments are over [16].

Person's sense of coherence (SOC) refers to an individual's orientation towards life and is a central concept of Antonovsky's theory of salutogenesis [17]. SOC may be described as a readiness of an individual to experience life as understandable, manageable and meaningful and to deal with stressors appropriately. Antonovsky's initial research focused on health promoting factors instead of health risks. Antonovsky hypothesized health as a continuum between total disease (dis-ease) and complete health (ease). The concept of salutogenesis challenges the traditional medical view on pathogenesis [17, 18]. SOC associates strongly with perceived LS and QoL [19].

BC patients with a strong SOC experience fewer stressful events and better overall QoL. The associations between, on the one hand, SOC and, on the other hand, health status, LS and QoL are linear [20, 21]. SOC, self-esteem, coping strategies, social support, global meaning and emotional distress are associated with QoL among patients with cancer. There is a positive link between self-esteem and QoL, and fighting spirit impacts positively on QoL [22].

Although the incidence of $\mathrm{BC}$ is increasing, the number of younger $\mathrm{BC}$ patients and consequently survivors is low and only few studies have addressed the LS and SOC among young BC survivors. Further, no comparative studies on LS between BC patients and other groups of patients suffering from common chronic diseases have been performed. 
The purpose of this study was to compare the LS and SOC of women with BC after initial recovery to LS and SOC of two groups of women suffering from common long-term conditions, i.e. mental depression and arterial hypertension, and to LS and SOC of healthy controls. According to the study hypothesis, recovery from BC could be detected as impaired LS and SOC among BC survivors in comparison with healthy controls, where we expected the greatest differences to appear, but we also expected differences in comparison to corresponding female patients with arterial hypertension or mental depression.

\section{Methods}

\subsection{Study Design and Participants}

The data of the study is drawn from The Health and Social Support (HeSSup) study which is an ongoing prospective cohort study on a nationwide representative sample of the Finnish population [23]. The study started in 1998 and four initial age groups have been followed up: 20-24, 30-34, 40-44 and 50-54 years. The total number of all participants is 25,895 , and female participants 15,267 .

The HeSSup survey data of year 2003 was used and, with the consent of the respondents, linked with national registry data from the years 1998-2012 of the Finnish Cancer Registry, the Finnish Drug Purchase and Imbursement Registry of the Social Insurance Institution, and mortality statistics from Statistics Finland. BC patients were followed-up for mortality until the end of 2012. The respondents who had a registered (verification by the Finnish Cancer Registry) diagnosis of BC in 1998-2002, were alive at least one year after diagnosis, and had completed the 2003 survey, formed the study group $(\mathrm{N}=56)$. No woman had to be excluded due to death. Also those women with $\mathrm{BC}$, who also had reported depression, were included. The patients with BC were followed-up for mortality until the end of 2012 when nine respondents with $\mathrm{BC}$ had died due to it. There were three study groups to be compared: (1) the respondents who reported having suffered from mental depression in the 2003 survey, had purchased antidepressants and were alive in 2003-2005 ( $\mathrm{N}=471)$; (2) the respondents who reported having arterial hypertension in the 2003 survey, had purchased anti-hypertensive medication and were alive in 2003-2005 ( $\mathrm{N}=841)$; and (3) all respondents of corresponding age who had not reported any chronic disease, any cancer, depression or hypertension $(\mathrm{N}=6274)$ in the 2003 survey.

Purchase of medication as well as survival was determined according to registry data. The survey data was with consent of the respondents linked with national registry data from the years 1998-2012 of the Finnish Cancer Registry, the Finnish Drug Purchase and Imbursement Registry of the Social Insurance Institution, and mortality statistics from Statistics Finland. Control disease groups with high incidence were selected for the study control group. These diseases are common public health problems among the study population in Finland. The advantage of using several control groups provides a basis for valid generalization. The study design and participants is presented in Fig. 1. 


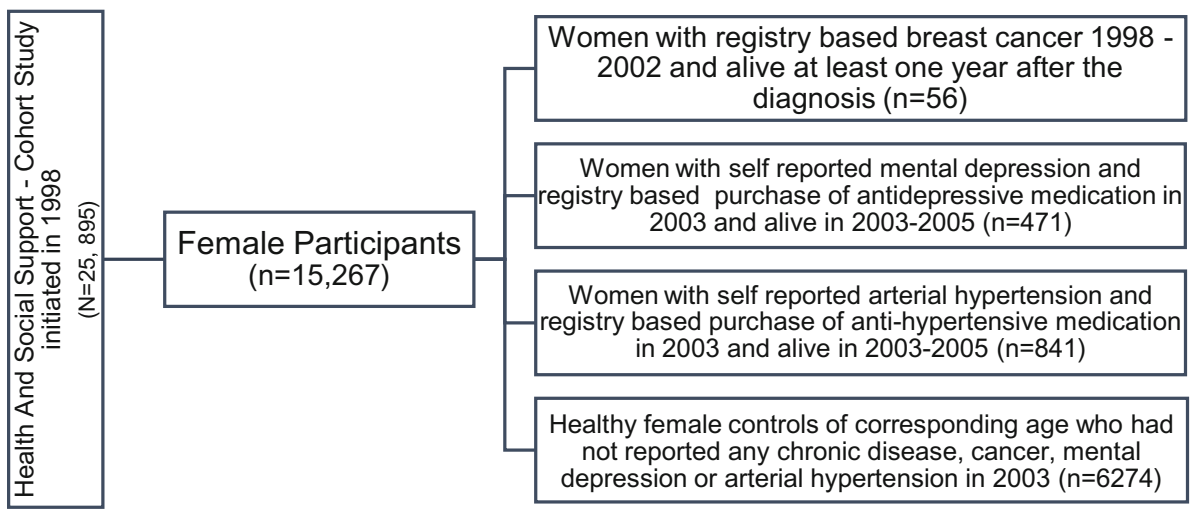

Fig. 1. Study design and participants

\subsection{Ethics}

Since the HeSSup study was not a medical study, the concurrent joint Ethics Committee of the University of Turku and the Turku University Central Hospital considered that formal approval was not needed and stated that the study followed the ethical guidelines for good scientific practice.

\subsection{Outcome Variables}

The data on the outcome variables were derived from the 2003 survey. Life satisfaction (LS) is an essential part of QoL. LS was assessed using a four-question scale modified from a questionnaire developed for measuring the QoL in Nordic QoL studies [24]. The participants were asked to rate four aspects of their life satisfaction: interest in life, happiness, ease of living and loneliness (Very interesting/Happy/Easy/Not at all = 1, Very boring/Unhappy/Hard/Lonely $=5$ ). The LS sum score (range: 4-20) was further classified into the following categories: satisfied (4-6), intermediately satisfied (7-11) and unsatisfied (12-20). The sum scale of LS variable was reversed for statistical processing so that a higher score corresponded to better life satisfaction and vice versa. A sum was calculated under the condition that at least three items were responded to. A missing value was replaced by the mean of the remaining three.

SOC was assessed using Antonovsky's 13-item scale [18] which is derived from the original 29-item Orientation to Life Questionnaire. It covers the three main sub-components of SOC: comprehensibility (5 items), manageability (4 items), and meaningfulness (4 items). All items have a seven graded (Likert-type) response scale, and a sum was calculated (range 13-91) under the condition that at least 3 comprehensibility, 2 manageability and 2 meaningfulness items were filled in. Missing values were replaced with the mean of other items in each sub-component.

The respondent's level of education was classified into four categories: no professional education; vocational course or school/apprentice contract: college, and university/other high level education. 


\subsection{Statistical Analyses}

The age group 20-24 years was omitted from the statistical analysis since there was only one respondent with $\mathrm{BC}$.

Overall associations between the variables were measured with the CochranMantel-Haenszel test. The following descriptive statistics were calculated: frequency, mean with $95 \%$ confidence interval, range and median. The ANOVA with pairwise comparison with Tukey-Kramer adjustment was used to determine differences between study groups. Pearson's correlation test was used to compare degrees of association between LS and SOC scale.

The limit for statistical significance was set at $\mathrm{p}=0.05$. Statistical analyses were performed with the SAS ${ }^{\circledR}$ software v.9.3 for Windows (SAS Institute Inc., USA).

\section{Results}

Respondents' age and educational background is presented in Tables 1 and 2. Most respondents were 40-44 years old, and most of them had vocational course/school or college education (Tables 1 and 2). The number of BC survivors after initial recovery was relatively low, as the age of participants was generally low. The age and educational distributions were consistent in each group which enables the comparisons between different groups.

Table 1. Number and \% of row sum of the women studied by age.

\begin{tabular}{l|r|r|r|r|r|r|r|r}
\hline Age & \multicolumn{3}{|l|}{$\begin{array}{l}30-34 \\
\text { years }\end{array}$} & \multicolumn{2}{l|}{$\begin{array}{l}40-44 \\
\text { years }\end{array}$} & \multicolumn{2}{l|}{$\begin{array}{l}\text { 50-54 } \\
\text { years }\end{array}$} & \multicolumn{2}{l}{ All } \\
\hline & Freq. & $\%$ & Freq. & $\%$ & Freq. & $\%$ & Freq. & $\%$ \\
\hline Breast cancer & 3 & 5.4 & 20 & 35.7 & 33 & 58.9 & 56 & 100 \\
\hline Depression & 138 & 29.3 & 187 & 39.7 & 146 & 31.0 & 471 & 100 \\
\hline Arterial hypertension & 70 & 8.3 & 215 & 25.6 & 556 & 66.1 & 841 & 100 \\
\hline Controls & 2330 & 37.1 & 2181 & 34.8 & 1763 & 28.1 & 6274 & 100 \\
\hline Total & $\mathbf{2 5 4 1}$ & $\mathbf{3 3 . 3}$ & $\mathbf{2 6 0 3}$ & $\mathbf{3 4 . 0}$ & $\mathbf{2 4 9 8}$ & $\mathbf{3 2 . 7}$ & $\mathbf{7 6 4 2}$ & $\mathbf{1 0 0 . 0}$ \\
\hline
\end{tabular}

\subsection{Life Satisfaction (LS)}

LS among women with BC, mental depression or arterial hypertension, and among healthy female controls is presented by age group and by age groups combined in Table 3.

When all age groups were combined there were no significant differences in LS between patients with BC, patients with hypertension or healthy participants, while the group with depression had significantly poorer LS compared to the rest (Table 3). All results for LS remained unchanged when adjusted for age and level of education. When analyzed according to age group, the result was particularly apparent among the oldest respondents (Table 3). The statistically significant differences in comparison with the group suffering from depression persisted except for the youngest age group. 
Table 2. Number and $\%$ of row sum of the women studied by education.

\begin{tabular}{l|l|l|l|l|l|l|l|l|l|l}
\hline Level of education & \multicolumn{2}{|l|}{$\begin{array}{l}\text { No. professional } \\
\text { education }\end{array}$} & \multicolumn{2}{l|}{$\begin{array}{l}\text { Vocational } \\
\text { course or } \\
\text { school/apprentice } \\
\text { contract }\end{array}$} & \multicolumn{2}{l}{$\begin{array}{l}\text { College } \\
\text { University higher }\end{array}$} \\
\hline & Freq. & $\%$ & Freq. & $\%$ & Freq. & $\%$ & Freq. & $\%$ & Freq. & $\%$ \\
\hline Breast cancer & 12 & 18.8 & 13 & 23.2 & 16 & 28.6 & 15 & 26.8 & 56 & 100 \\
\hline Depression & 67 & 14.2 & 154 & 32.7 & 175 & 37.2 & 72 & 15.3 & 468 & 100 \\
\hline Arterial hypertension & 158 & 18.8 & 289 & 34.4 & 308 & 36.6 & 79 & 9.4 & 834 & 100 \\
\hline Controls & 764 & 12.2 & 1886 & 30.1 & 2519 & 40.4 & 1057 & 24 & 6226 & 100 \\
\hline Total & $\mathbf{1 0 0 1}$ & $\mathbf{1 3 . 2}$ & $\mathbf{2 3 4 4}$ & $\mathbf{3 0 . 9}$ & $\mathbf{3 0 2 1}$ & $\mathbf{3 9 . 8}$ & $\mathbf{1 2 2 6}$ & $\mathbf{1 6 . 1}$ & $\mathbf{7 5 8 2}$ & $\mathbf{1 0 0}$ \\
\hline
\end{tabular}

Table 3. Life satisfaction sum scores of women with registry based breast cancer, self-reported and medicated mental depression and self-reported and medicated arterial hypertension and of healthy women controls by age groups and age groups combined. The values in the columns additionally to age and $\mathrm{N}$ stand for Range, Mean with $95 \%$ confidence interval (CL), median and observed statistical significance.

\begin{tabular}{l|l|l|l|l|l}
\hline Group & Age & $\mathrm{N}$ & Range & Mean $(95 \% \mathrm{CI})$ & Median \\
\hline Breast cancer & $30-34$ & 3 & $13.0-14.0$ & $13.7(12.2-15.1)$ & 14.0 \\
\hline & $40-44$ & 20 & $7.0-19.0$ & $15.2(13.8-16.5)$ & 16.5 \\
\hline Mental depression & $50-54$ & 33 & $7.0-20.0$ & $15.8(14.8-16.9)$ & 17.0 \\
\hline & $30-34$ & 138 & $5.0-20.0$ & $13.8(13.2-14.5)$ & 15.0 \\
\hline & $40-44$ & 187 & $4.0-20.0$ & $13.1(12.5-13.7)$ & 14.0 \\
\hline Arterial hypertension & $50-54$ & 146 & $6.0-20.0$ & $13.8(13.2-14.4)$ & 15.0 \\
\hline & $30-34$ & 70 & $8.0-20.0$ & $15.5(14.8-16.2)$ & 17.0 \\
\hline & $40-44$ & 215 & $5.0-20.0$ & $15.0(14.6-15.5)$ & 17.0 \\
\hline Controls & $50-54$ & 556 & $4.0-20.0$ & $15.5(15.2-15.8)$ & 17.0 \\
\hline & $30-34$ & 2300 & $4.0-20.0$ & $15.6(15.4-15.7)$ & 17.0 \\
\hline & $40-44$ & 2181 & $4.0-20.0$ & $15.5(15.4-15.6)$ & 17.0 \\
\hline Age groups combined & $50-54$ & 1763 & $4.0-20.0$ & $15.7(15.6-15.9)$ & 17.0 \\
\hline Breast cancer & $\mathrm{N}$ & Range & Mean $(95 \%$ CI $)$ & Median & p* \\
\hline Mental depression & 56 & $7.0-20.0$ & $15.5(14.7-16.3)$ & 17.0 & Ref. \\
\hline Arterial hypertension & 471 & $4.0-20.0$ & $13.5(13.2-13.9)$ & 15.0 & 0.0001 \\
\hline Controls & 841 & $4.0-20.0$ & $15.4(15.2-15.6)$ & 17.0 & 0.9971 \\
\hline
\end{tabular}

*Tukey-Kramer test for pairwise mean differences between BC and other groups.

\subsection{Sense of Coherence (SOC)}

Individuals with mental depression had the lowest SOC scores in each age group; the nadir was for the age group 30-34 years. In the younger age groups the differences in SOC between BC survivors and healthy controls were the greatest. The younger age groups had overall lower SOC scores than the older ones. The differences were, however, not statistically significant. The individuals with $\mathrm{BC}$ in age group 50-54 
years had higher SOC scores than individuals of same age in any other group. The individuals with arterial hypertension had lower SOC scores than individuals in BC group when the age groups were analyzed together. These differences were not statistically significant, except for the depression group (Table 4).

Table 4. Sense of coherence scores of women with registry based breast cancer, self-reported and medicated mental depression and self-reported and medicated arterial hypertension and of healthy female controls by age groups and age groups combined. The values in the columns additionally to age and $\mathrm{N}$ stand for Range, Mean, Median, and $95 \%$ confidence interval. $\mathrm{CI}=$ confidence interval.

\begin{tabular}{l|l|l|l|l|l}
\hline Group & Age & $\mathrm{N}$ & Range & Mean $(95 \% \mathrm{CI})$ & Median \\
\hline Breast cancer & $30-34$ & 3 & $60.0-62.0$ & $61.0(58.5-63.5)$ & 61.0 \\
\hline & $40-44$ & 20 & $29.0-82.0$ & $62.9(56.8-69.0)$ & 65.0 \\
\hline Mental depression & $50-54$ & 33 & $44.0-86.0$ & $69.7(66.1-73.3)$ & 69.0 \\
\hline & $30-34$ & 138 & $24.0-86.0$ & $58.3(56.1-60.4)$ & 59.0 \\
\hline & $40-44$ & 187 & $19.0-91.0$ & $58.4(56.6-60.2)$ & 59.0 \\
\hline Arterial hypertension & $50-54$ & 146 & $32.0-86.0$ & $60.2(58.2-62.1)$ & 61.0 \\
\hline & $30-34$ & 70 & $37.0-87.0$ & $66.6(62.8-68.5)$ & 68.0 \\
\hline & $40-44$ & 215 & $25.0-90.0$ & $65.6(64.0-67.2)$ & 68.0 \\
\hline Controls & $50-54$ & 556 & $25.0-90.0$ & $66.4(65.5-67.3)$ & 67.0 \\
\hline & $30-34$ & 2330 & $25.0-91.0$ & $66.1(65.7-66.6)$ & 67.0 \\
\hline & $40-44$ & 2181 & $20.0-91.0$ & $67.0(66.6-67.5)$ & 68.0 \\
\hline Age groups combined & $50-54$ & 1763 & $28.0-90.0$ & $68.3(67.8-68.8)$ & 69.0 \\
\hline Breast cancer & $\mathrm{N}$ & Range & Mean $(95 \%$ CI $)$ & Median & p* \\
\hline Mental depression & 56 & $29.0-86.0$ & $66.8(63.7-69.9)$ & 67.7 & Ref.** \\
\hline Arterial hypertension & 471 & $19.0-91.0$ & $58.9(57.8-60.0)$ & 59.0 & $<0.0001$ \\
\hline Controls & 841 & $25.0-90.0$ & $66.1(65.4-66.9)$ & 67.0 & 0.9705 \\
\hline
\end{tabular}

*Tukey-Kramer test for pairwise mean differences between BC and other groups.

Overall, the healthy controls had the highest SOC scores in all other age groups except age group 50-54 years (Table 4), but the differences were not statistically significant compared to the other groups except for the depression group which, as stated above, had the poorest SOC.

There was a positive correlation $\left(\mathrm{r}^{2}=0.36, \mathrm{p}<0.001\right)$ between SOC and LS, i.e., the higher the SOC, the better the LS.

\section{Discussion}

Contrary to the study hypothesis the results showed that women with BC in their initial recovery phase, at least one year after diagnosis, did not have impaired LS and SOC. Compared to healthy female controls and the group of women with arterial hypertension there were no significant differences between women with BC and the other groups. However, women with depression reported significantly lower LS and SOC 
scores than the other groups. These results were particularly apparent when all the age groups were combined.

This is an interesting finding, since BC diagnosis has generally been reported to raise fear of death and distress $[10,18]$. Moreover, the sample included also those participants with BC, who also had self-reported depression in the 2003 survey. However, one has to keep in mind that the LS improves with the number of post-diagnosis years [25], and women with $\mathrm{BC}$ in this study were young and thus highly selected. Moreover, individuals with the poorest prognosis were possibly not alive one year after diagnosis or may due to this or other reasons not have participated in the second data collection of the HeSSup survey at all. This implies that the disease was for many individuals considered treatable and even completely curable which probably has provided new hope and improved their LS and strengthened their SOC. BC treatment has evolved over the years, and at present the survival of BC patients in Finland is excellent with $90 \%$ 5-years survival [2]. This most likely has an impact on the SOC and LS of the patients. Moreover, most BC patients have also already recovered from the acute crisis the disease with great probability has caused to most of them.

The LS of women with BC in this study was relatively good. It seems that women may have a sense of relief after having survived at least a year after the diagnosis. Ashing-Giwa et al. [26] reported similar findings on improved health status and relatively good overall QoL in African-American and Caucasian BC groups. Also Yost et al. [27] and Hsu et al. [28] have reported good LS among BC survivors. This may be due to the fact that the worst phase of the disease and crisis has passed, and the survivors may have received support services during their disease, which may have contributed to the process of surviving and the maintenance and improvement of LS.

To our knowledge, the design of the present study is unique in that it compares LS and SOC of women in initial recovery phase from BC with LS and SOC of two groups of women suffering from common long-term conditions, i.e. mental depression or arterial hypertension, and with LS and SOC of healthy female controls. The 4-item life satisfaction scale is easily administered and well accepted [23]. The 13-item SOC questionnaire, equally easy to administer, has been applied in a number of population studies [19]. Our study groups were mutually exclusive and the participants were entered into one study group only, except for the women with BC in which women suffering from mental depression were not excluded, whereas depressed individuals were excluded from the hypertension and control groups. Due to small numbers of women diagnosed with $\mathrm{BC}$, the exclusion of those $\mathrm{BC}$ patients with depression may have led to biased conclusions. However, in order to explore the potential influence of having included women with mental depression matching the study criteria into the group with $\mathrm{BC}$, additional statistical analyses were performed by excluding these individuals $(\mathrm{N}=11)$ yielding unchanged key results (data not shown).

The patients with BC were followed-up for mortality until the end of 2012 when nine respondents with $\mathrm{BC}$ had died due to it. This extended follow-up increases the reliability of the results and confirms that results obtained are not due to selection bias (i.e., only patients with the best prognosis have responded).

$\mathrm{BC}$ is a serious disease, and one would assume that the diagnosis would certainly affect the patients' LS and SOC [10, 29, 30]. Younger age in women with BC has been shown to be one of the significant risk factors for poor LS and greater psychological 
morbidity compared to older women [31, 32]. Many BC survivors report weakened LS and younger BC survivors are at risk for impaired LS up to several years after diagnosis [32]. There is also evidence that mental depression is one of the symptoms or a consequence of the cancer diagnosis [33].

Based on our results, it seems that during the survival phase, after the acute crisis, LS might improve. Cancer, as a frightening disease at the time of diagnosis, may weaken LS, but coping with the disease even improves it - serious illness and the survival becomes as a part of survivors' own history. The conclusion is consistent with previous findings showing that coping with a serious disease leads to hope and gratitude, and growth and empowerment [34]. Coping raises patient's fighting spirit against the disease and improves current LS. The way of coping with fears and long-term effects might be predictors for long-term LS after cancer [34, 35].

More studies are still needed to examine factors affecting the LS, which form an important base for the development of cancer rehabilitation and treatment. BC treatment is currently rather well structured and harmonized in Finland so that rehabilitation is usually offered after treatment, usually more than a year from diagnosis. It has been shown, however, that people with cancer need peer, psychosocial and physical support and information about cancer during the disease [36]. Structured measurement of LS enables comparisons between a variety of diseases and treatments, which is needed for decisions within health care, especially when nationwide health policies for cancer patients are organized.

Untreated mental depression clearly impairs the overall QoL. Depression understandably affects LS negatively and most of the loss of LS associated with chronic diseases may be attributed to mental disorders. The patient's perception of the severity of her disease is related to the complexity of the disease and to a number of areas of life that are affected by the symptoms [15]. These observations explain some of the present findings, e.g., that depression was associated with the poorest LS and SOC, even considering the use of antidepressants. Indeed, treatment of depression does improve LS, but depression is still associated with a poor overall QoL even when the patient is on medication [37].

SOC lies within the domain of a person's health resources and, in that, SOC influences LS and overall QoL [19]. There is substantial evidence that SOC plays a central role in a patient's coping with stressors during rehabilitation or recovery and that SOC contributes to mental health and psychosocial functioning [38]. Our results support Antonovsky's theoretical assumptions of SOC [17]. LS was linearly associated with SOC, i.e., the stronger the SOC, the better the LS. Zielińska-Więczkowska et al. [39] have found that a strong SOC and high level of education have significant effects on LS. In our study, however, the educational background had no significant impact on the results.

The results can only be generalized to young women with BC (aged below 55 years) without any comorbidity. Age is inversely associated with LS [40]. The group of $\mathrm{BC}$ patients in this study represents a very special group, as majority of BC patients in general population are over 60 years. Young BC patients may have special needs for rehabilitation and psychosocial support, which needs to be investigated further. In Finland, practically all BC patients, in addition to medical treatment, undergo various supplementary interventions. The study lends support to the efficiency of these 
interventions. Unfortunately, no information about the interventions on the individual level is available. Hence, more studies on determinants of the efficiency of these interventions are needed.

During the recent decades, 5-year survival rates have improved among cancer patients who are otherwise healthy, but not among individuals with severe comorbidities [41]. Overall QoL and outcomes from most functional and symptom scales seem to weaken over time [29]. Apparently patients with cancer and psychological symptoms and depression have a poorer LS [14] and patients with BC have generally a high incidence of depression and anxiety and a reported low LS [31].

At the baseline HeSSup study, the study participation rate was moderate, only $40 \%$. Nevertheless, an analysis of non-respondents has shown that the sample regarding health parameters is representative for the Finnish population [23]. The probability of not responding was greater among men, older age groups, those with less education, divorced or widowed respondents and respondents on disability pension. It has been shown that respondents tend to be healthier and report a more favorable health behavior than non-respondents [23]. It is also known that women and those of a higher social class tend to participate more actively in health-related survey research than males and persons of lower social class. This may lead to underestimation of the prevalence of health problems among men and persons of lower social strata. Another theory which explains passive or active responses to health issues is SOC. It has been found to have a strong positive impact on health information literacy [42].

The strengths of the study include the use reliable registry data, so we did not need to rely solely on self-reported data. According to concurrent legislation, The Finnish Cancer Registry registers all cancer cases in Finland and all medication is registered by The Finnish Drug Purchase and Imbursement Registry of the Social Insurance Institution, so the allocation of patients within groups is reliable. Other strengths are the extensive source data of more than 15,000 women, and careful follow-up of the individuals in the study. Even though the BC patient group is small, it can be considered reliable and unbiased. As the number of young (under 55 years) BC survivors is generally low, this places this research data in a unique position.

In summary, after at least initial recovery from BC, LS and SOC do not seem to be permanently affected on a group level since the women studied were rather satisfied with their lives and reported a good level of SOC. Women recovering from BC were in fact as satisfied with their life as healthy controls. The SOC and LS also inter-correlated statistically significantly in accordance with earlier findings. However, factors affecting LS and SOC need to be examined and described more in detail in the future for designing and organizing optimal supportive health care and rehabilitation services for BC survivors.

\section{Conclusions}

After at least initial recovery from BC, LS and SOC do not seem to be permanently affected on a group level since the women studied were rather satisfied with their lives and reported a good level of SOC. Women recovering from BC were in fact as satisfied 
with their life as healthy controls. The SOC and LS also inter-correlated statistically significantly in accordance with earlier findings.

However, factors affecting LS and SOC need to be examined and described more in detail in the future for achieving even improved supportive health care and rehabilitation services for BC survivors.

\section{References}

1. Globocan 2012. Fast Stats. Most frequent cancers: women. http://globocan.iarc.fr/factsheets/ populations/factsheet.asp?uno=900\#WOMEN. Accessed 05 Jan 2016

2. Finnish Cancer Registry. http://www.cancer.fi/syoparekisteri/en/statistics/cancer-statistics/. Accessed 10 Jan 2016

3. Cella, D.F.: Quality of life: concepts and definition. J. Pain Symptom Manag. 9, 186-192 (1994)

4. Allardt, E.: Hyvinvoinnin ulottuvuudet. WSOY, Porvoo (1976)

5. Veenhoven, R.: The Study of Life Satisfaction. Eötvös University Press, Budapest (1996). ISBN 963463081 2, pp. 11-48

6. Cella, D., Cherin, E.: Quality of life during and after treatment. Compr. Ther. 14, 69-75 (1988)

7. Mols, F., Vingerhoets, A.J., Coebergh, J.W., Poll-Franse, L.V.: Quality of life among long-term breast cancer survivors: a systematic review. Eur. J. Cancer 2005(41), 2613-2619 (2005)

8. Garnefski, N., Kraaij, V., Spinhoven, P.: Negative life events, cognitive emotion regulation and emotional problems. Pers. Individ. Differ. 2001(30), 1311-1327 (2001)

9. Lehto, U.S., Ojanen, M., Kellokumpu-Lehtinen, P.: Predictors of quality of life in newly diagnosed melanoma and breast cancer patients. Ann. Oncol. 16, 805-816 (2005)

10. Yusuf, A., Ahmad, Z., Keng, S.L.: Quality of life in Malay and Chinese women newly diagnosed with breast cancer in Kelantan Malaysia. Asian Pac. J. Cancer Prev. 14, 435-440 (2013)

11. Carlson, L.E., Bultz, B.D.: Cancer distress screening: needs, models, and methods. J. Psychosom. Res. 55(5), 403-409 (2003)

12. Stark, D., Kiely, M., Smith, A., Velikova, G., House, A., Selby, P.: Anxiety disorders in cancer individuals: their nature, associations, and relation to quality of life. J. Clin. Oncol. 20 (14), 3137-3148 (2014)

13. So, W.K.W., Marsh, G., Ling, W.M., Leung, F.Y., Lo, J.C.K., Yeung, M., Li, G.: Anxiety, depression and quality of life among Chinese breast cancer individuals during adjuvant therapy. Eur. J. Oncol. Nurs. 14(1), 17-22 (2010)

14. Howard-Anderson, J., Ganz, P.A., Bower, J.E., Stanton, A.L.: Quality of life, fertility concerns, and behavioral health outcomes in younger breast cancer survivors: a systematic review. J. Natl. Cancer Inst. 104(5), 386-405 (2012)

15. Saarni, S.: Health-related quality of life and mental disorders in Finland. Department of Mental Health and Alcohol Research National Public Health Institute, Helsinki and Department of Psychiatry University of Helsinki, Helsinki, Finland (2008)

16. Holzner, B., Kemmler, G., Kopp, M., Moschen, M., Schweigkofler, H., Dünser, M., Margreiter, R., Fleischhacker, W.W., Sperner-Unterweger, B.: Quality of life in breast cancer individuals — not enough attention for long-term survivors? Psychosomatics 42, 117$123(2001)$ 
17. Schumacher, J., Wilz, G., Gunzelmann, T., Brahler, E.: The Antonovsky sense of coherence scale. Test statistical evaluation of a representative population sample and construction of a briefscale. Psychother. Psychosom. Med. 50, 472-482 (2000)

18. Antonovsky, A.: Unraveling the Mystery of Health. How People Manage Stress and Stay Well San Francisco. Jossey-Bass, London (1987)

19. Eriksson, M., Lindström, B.: Antonovsky's sense of coherence scale and its relation with quality of life: a systematic review. J. Epidemiol. Commun. Health 61(11), 938- 944 (2007)

20. Sarenmalm, K.E., Browall, M., Persson, L.-O., Fall-Dickson, J., Gaston-Johansson, F.: Relationship of sense of coherence to stressful events, coping strategies, health status, and quality of life in women with breast cancer. Psycho-Oncology (2011). doi:10.1002/pon.2053

21. Gerasimčik-Pulko, V., Pileckaitė-Markovienè, M., Bulotienė, G., Ostapenko, V.: Relationship between sense of coherence and quality of life in early stage breast cancer individuals. Acta Med. Litu. 16(3-4), 139-144 (2009)

22. Allart, P., Soubeyran, P., Cousson-Gélie, F.: Are psychosocial factors associated with quality of life in individuals with haematological cancer? A critical review of the literature. Psycho-Oncology 22(2), 241-249 (2013). doi:10.1002/pon.3026

23. Korkeila, K., Suominen, S., Ahvenainen, J., Ojanlatva, A., Rautava, P., Helenius, H., Koskenvuo, M.: Non-response and related factors in a nation-wide health survey. Eur. J. Epidemiol. 17, 991-999 (2001)

24. Allardt, E.: About dimension of welfare: an explanatory analysis of the comparative Scandinavian survey. University of the Helsinki, Research Group of Comparative Sociology Research reports, no.1 (1973)

25. Cimprich, B., Ronis, D.L., Martinez-Ramos, G.: Age at diagnosis and quality of life in breast cancer survivors. Cancer Pract. 10, 85-93 (2002)

26. Ashing-Giwa, K., Ganz, P.A., Petersen, L.: Quality of life of African-American and white long term breast carcinoma survivors. Cancer 85, 418-426 (1999)

27. Yost, K.J., Haan, M.N., Levine, R.A., Gold, E.B.: Comparing SF-36 scores across three groups of women with different health profiles. Qual. Life Res. 14(5), 1251-1261 (2005)

28. Hsu, T., Ennis, M., Hood, N., Graham, M., Goodwin, P.: Quality of life in long term breast cancer survivors. Am. Soc. Clin. Oncol. 31, 3540-3548 (2013)

29. Bloom, J., Stewart, S., Oakley-Girvan, I., Banks, I.: Quality of life of younger breast cancer survivors: persistence of problems and sense of well-being. Psycho-Oncology 21(6), 655665 (2012)

30. Helgeson, V.S., Snyder, P., Seltman, H.: Psychological and physical adjustment to breast cancer over 4 years: identifying distinct trajectories of change. Health Psychol. 23(1), 3-15 (2004)

31. Kwan, M.L., Ergas, I.J., Somkin, C.P., Quesenberry Jr., C.P., Neugut, A.I., Hershman, D.L., et al.: Quality of life among women recently diagnosed with invasive breast cancer: the pathways study. Breast Cancer Res. Treat. 123, 507-524 (2010)

32. Avis, N.E., Crawford, S., Manuel, J.: Quality of life among younger women with breast cancer. J. Clin. Oncol. 23, 3322-3330 (2005)

33. Weitzner, M.A., Meyers, C.A., Stuebing, K.K., Saleeba, A.K.: Relationship between quality of life and mood in long-term survivors of breast cancer treated with mastectomy. Support. Care Cancer 5, 241-248 (1997)

34. Chopra, I., Kamal, K.: A systematic review of quality of life instruments in long-term breast cancer survivors. Health Qual. Life Outcomes 10, 14 (2012). doi:10.1186/1477-7525-10-14

35. Dahl, L., Wittrup, I., Væggemose, U., Petersen, L.K., Blaakaer, J.: Life after gynecologic cancer-a review of individuals quality of life, needs, and preferences in regard to follow-up. Int. J. Gynecol. Cancer 23(2), 227-234 (2013). doi:10.1097/IGC.0b013e31827f37b0 
36. Dilworth, S., Higgins, I., Parker, V., Kelly, B., Turner, J.: Individual and health professional's perceived barriers to the delivery of psychosocial care to adults with cancer: a systematic review. Psycho-Oncology 23(6), 601-612 (2014). doi:10.1002/pon. 3474

37. IsHak, W.W., Greenberg, J.M., Balayan, K., Kapitanski, N., Jeffrey, J., Fathy, H., Fakhry, H., Rapaport, M.H.: Quality of life: the ultimate outcome measure of interventions in major depressive disorder. Harv. Rev Psychiatry 19(5), 229-239 (2011)

38. Griffiths, C.A.: Sense of coherence and mental health rehabilitation. Clin. Rehabil. 23(1), 72-78 (2009). doi:10.1177/0269215508095360

39. Zielińska-Więczkowska, H., Ciemnoczołowski, W., Kędziora-Kornatowska, K., Muszalik, M.: The sense of coherence (SOC) as an important determinant of life satisfaction, based on own research, and exemplified by the students of University of the Third Age (U3A). Arch Gerontol. Geriatr. 54(1), 238-241 (2012). doi:10.1016/j.archger.2011.03.008

40. Knobf, M.: Psychosocial responses in breast cancer survivors. Semin. Oncol. Nurs. 23(1), 71-83 (2007)

41. Søgaard, M., Thomsen, R., Bossen, K., Sørensen, H., Nørgaard, M.: The impact of comorbidity on cancer survival: a review. Clin. Epidemiol. 5(1), 3-29 (2013). doi:10.2147/ CLEP.S47150

42. Ek, S., Widén-Wulff, G.: Information mastering, perceived health and societal status: an empirical study of the Finnish population. Libri 58(2), 74-81 (2008) 